\title{
As lindas toilletes de Aymond: performance de gênero como trabalho (1920-1950)
}

Flavia Ribeiro Veras

\section{RESUMO}

O presente artigo apresenta esforço no sentido de promover diálogo entre os campos da história social do trabalho e dos estudos de gênero através da trajetória profissional do artista transformista Norberto Aymonino e de sua personagem Aymond. $\mathrm{O}$ artista argentino, que se apresentou nos palcos brasileiros entre 1920 e 1955, tinha talento reconhecido e ostentava beleza e luxuosidade. Ao mesmo tempo que ele firmava contratos com importantes empresas do ramo das diversóes, não lograva reconhecimento como grandes artistas, nem os mesmos valores de cachês pagos a outros artistas de variedades. Procuramos analisar como tal diferença profissional entre os artistas transformistas e demais intérpretes foi produzida e vivenciada a partir da experiência de Aymond.

Palavras-chave: artista transformista; gênero; trabalho.

\section{Aymond's fancy wardrobe: gender performance as work (1920-1950)}

\section{ABSTRACT}

This paper is an effort to promote dialogue between the fields of labor and gender studies through an analysis of the professional career of the cross-dressing artist Norberto Aymonino and his character Aymond. The Argentine artist, who performed on Brazilian stages between 1920 and 1955, had recognized talent, beauty, and style, and he signed contracts with Brazil's leading entertainment companies. Nevertheless, he won less recognition and was paid less than other variety artists. This article uses Aymond's experience to analyze such contrasts between the careers of professional drag queens and other performers.

Keywords: cross-dressing artist; gender; labor.

DOI: http://dx.doi.org/10.1590/2237-101X02204709

Artigo recebido em 9 de abril de 2020 e aceito para publicação em 5 de agosto de 2020.

* Doutora pela Fundação Getúlio Vargas, CPDOC, Programa de Pós-Graduação em História, Política e Bens Culturais do Centro de Pesquisa e Documentação de História Contemporânea do Brasil, Rio de Janeiro/RJ - Brasil. E-mail: verasf06@gmail.com. ORCID: https:/orcid.org/0000-0002-6669-4629. 


\title{
Las bellas toilettes ${ }^{1}$ de Aymond: performance de genero como trabajo (1920-1950)
}

\section{RESUMEN}

Este artículo presenta un esfuerzo por promover el diálogo entre los campos de la historia social del trabajo y los estudios de género a través de la trayectoria profesional del artista transformista Norberto Aymonino y su personaje Aymond. El artista argentino que actuó en escenarios brasileños entre 1920 y 1955 había reconocido el talento y también presumía de belleza y lujo. Si bien firmó contratos con las principales compañías de entretenimiento, no ganó reconocimiento, ni pago como los otros artistas de variedades. Buscamos aquí analizar cómo se produce y experimenta esta diferencia profisional entre artistas a partir de la experiencia de Aymond.

Palabras clave: artista transformista; gênero; trabajo.

\author{
O que que há \\ O que que há \\ Você dizendo que é o Tirone Povér \\ Porém com essa cabeleira \\ Você parece Ava Gardinér. \\ Moço que usa topete \\ Só se compromete \\ Mulher é que se enfeita como pode \\ Enfeite de homem \\ É bigode!
}

Essa marchinha de carnaval foi gravada por Dircinha Batista em 1955. Ela nos leva a refletir sobre a forma como o mercado de diversôes representou e diferenciou os indivíduos por estereótipos de gêneros em meados do século XX. Através do humor marcavam-se traços do exotismo, ao mesmo tempo que se produziam o riso e o desprezo. Essa música se popularizou já no final da carreira artística de Norberto Aymonino. O tom jocoso impresso na letra da canção nos ajuda a entender parte das dificuldades profissionais de nossa personagem. A diferenciação de comportamentos considerados femininos e masculinos apareceu na fonte impregnada de noçôes sobre valores e funçôes sociais. Ela expõe as normatizaçôes sobre

\footnotetext{
${ }^{1}$ O termo conserva a grafia usada em reportagem publicada pelo Diário da Manhã, Recife/PE, em 27 de dezembro de 1941: "A vida da Cidade. Aymond, o transformista e outros artistas".
} 
gênero como produtor de desigualdades que definiram margens de inclusão e exclusão na sociedade na qual vivia Norberto.

O objetivo deste artigo é analisar, através da trajetória profissional de Norberto Américo Aymonino, como noçôes de gênero e suas formas de manifestaçôes criaram condiçôes especiais para os artistas transformistas projetarem suas ambiçôes profissionais. Essa tarefa não foi simples. Ela requereu muitas estratégias de diferenciação e construção de redes de solidariedade entre os seus pares, o esforço para afirmar certa moralidade no meio artístico, o apelo ao profissionalismo e - o que dificultou muito o trabalho de pesquisa - a ocultação de informaçôes ao público e à imprensa. Norberto, como transformista e cantor, buscou se manter empregado em bons estabelecimentos como teatros, cassinos e festas promovidas por pessoas das altas classes sociais. Ele aceitava baixos cachês, ainda que seu público fosse em grande parte da elite. Ao mesmo tempo que recebia pagamento inferior a seus companheiros de palco, era reconhecido pelo talento artístico como cantor e transformista. Nos tablados, através da personagem chamada Aymond, ele atuava corporificando uma mulher elegante, luxuosa e dona de uma voz lírica, com a qual imitava as reconhecidas cantoras populares de sua época.

As fontes usadas para a elaboração deste artigo são compostas de periódicos, fundos oficiais presentes no Arquivo Nacional do Rio de Janeiro - a Delegacia de Costumes e Diversões Públicas e o Serviço de Comunicaçôes do Ministério da Justiça e Negócios Interiores, documentos privados da Casa dos Artistas no Rio de Janeiro, além de material catalogado pelo blog Obscuro Fichário de Artistas Mundanos². Foram analisados os anúncios de apresentaçôes, a forma como o artista era anunciado pela imprensa, a rotina de contratos, os cachês recebidos e dados pessoais fornecidos por Norberto para a polícia.

É importante ressaltar que existe uma profunda deficiência nos arquivos brasileiros no que diz respeito a catalogação e ferramentas de pesquisa para investigação em temas LGBTQIA+. No Rio de Janeiro, o Museu da Imagem e do Som (MIS) tem feito açóes no sentido de promover o debate sobre diversidade. Contudo, apesar dos esforços, por falta de investimentos ainda não é possível ver mudanças na sua política arquivística. $\mathrm{Na}$ Funarte, que tem a guarda de grandioso acervo sobre o universo artístico - contando com programas teatrais, arquivos pessoais, produção audiovisual, impressos, entre outros - é difícil a busca específica por artistas LGBTQIA+, transformistas ou drag queens. Por um lado, esse desinteresse mostra a marginalidade dessas performances e o pouco interesse dos meios institucionais de pensá-las no conjunto das produçóes artísticas. Por outro, dificulta o trabalho de investigação sobre o tema e, consequentemente, provoca seu apagamento tanto na história das artes e da performance teatral no Brasil, como também contribui para o apagamento da memória LGBTQIA+ como um todo. Grande parte da documentação disponível sobre o tema, que

\footnotetext{
${ }^{2} \mathrm{Blog}$ de pesquisadores que se dedica a pesquisar e revelar biografias de artistas esquecidos pelo público. A investigação se deu em escala nacional e englobou a análise de periódicos e os arquivos das Delegacias de Costumes e Diversões Públicas. Disponível em: http://obscurofichario.com.br. Acesso em: 5 dez. 2019.
} 
não seja de natureza policial ou médica, está sob guarda pessoal e/ou disponibilizada virtualmente por esforço dos próprios militantes.

\section{Artista transformista: entre a história do trabalho e os estudos de gênero}

Este trabalho se insere na interseção do campo da história social do trabalho com o campo dos estudos de gênero e sexualidade. Ambos têm em comum certa simbiose com o ativismo de seus militantes, constituindo-se como espaços acadêmicos e de luta social. Apesar de consolidado na academia e com longa trajetória de estudos, o campo da história social do trabalho passou por uma forte oxigenação a partir dos estudos de E. P. Thompson, que criou espaço para o debate de questôes culturais e identitárias até então pouco valorizadas (FORTES, 2016). A ampliação dos temas da história social do trabalho tem possibilitado a abertura de frentes de pesquisas, muitas vezes em abordagens interseccionais e transbordando os estudos tradicionais que durante muito tempo permaneceram concentrados no proletariado masculino e branco em sua luta fabril.

Por outro lado, o campo dos queer studies é bem mais novo. No Brasil, na área da história, tem despertado grande interesse acadêmico nos últimos anos. Esse movimento é perceptível na organização de simpósios, como na ANPUH de 2019, na qual foram apresentados pelo menos três GTs tratando explicitamente do tema de gênero e sexualidades (VILELA, 2019). Como também na emergência de grupos de pesquisas em muitas universidades do país, tais como o Laboratório de Estudos de Gênero e História (LEGH) da UFCS, o Núcleo de Pesquisa e Extensão em Gênero e Sexualidade (NuCus) vinculado à UFBA, o Grupo de Estudos e Pesquisas em História, Gênero e Sexualidade (GEPHGS) na UFAL e o Centro de Referência da História LGBTQIA+ do Rio Grande do Sul (Close).

Mesmo considerando os estudos nos EUA e na Europa, os queer studies se constituem como campo de investigação acadêmica recente. Spargo (2017) apontou que o uso da palavra queer pelos movimentos sociais e pela intelectualidade data do final dos anos 1980. Esse foi um processo de ressignificação, pois, podendo ser traduzido como esquisito ou bizarro, queer era usado pejorativamente para ofender pessoas homossexuais e travestis. $\mathrm{Na}$ esteira da revolta de Stonewall na década de 1960 surgiram, no campo da sociologia (não mais restrito à medicina), os primeiros interesses acadêmicos sobre a questão das homossexualidades (DUBERMAN, 1994).

A "performance de gênero" é uma das categorias que surgiram nesse processo recente da construção do campo dos queer studies. Ao mesmo tempo que a formulação de novas categorias e a emergência de identidades sociais ampliam as possibilidades de estudo e reflexão, mostram-se como um desafio para quem atua na escrita da história. Isto porque a ameaça de anacronismo aparece como uma armadilha constante. Contudo, é preciso encarar esse desafio como parte do trabalho no tempo presente. 
Sem considerar novas visôes, conceitos e ferramentas de pesquisa poderíamos interpretar que Norberto teve uma carreira de relativo sucesso e que as piadas de mau gosto ao apresentá-lo eram apenas "parte do show". Isto seria uma análise rasa sobre os transformistas no mundo do trabalho artístico no período recortado. Joan Scott (1989) e Judith Butler (2013), em momentos históricos e dinâmicas diferentes, entenderam o gênero como produtor de diferenças e apontaram a necessidade de ampliar as fronteiras desse campo de estudo, percebendo que binaridade conformava vulnerabilidades invisibilizadas. Michelle Perrot (2017), autora clássica dos estudos das mulheres, ofereceu uma contribuição teórica-metodológica fundamental ao denunciar a invisibilidade de sujeitos que não possuem história, não por não existirem, mas por uma exclusão dos espaços de produção do saber, o que geraria esses apagamentos.

Em entrevista para a Revista Manchete em $1953^{3}$, a artista de variedades e transformista Ivana, declarara que Norberto, com quem tinha contato pessoal, fora a primeira travesti do teatro brasileiro. Mesmo com essa declaração de Ivana não atribuo a Norberto a identidade de uma pessoa trans ou travesti neste artigo. Essas categorias têm sua própria historicidade e a identificaçáa pessoal passa por processos que têm a ver com o autoconhecimento em diálogo com as lutas sociais de seu tempo. Essas categorias e o valor que hoje atribuímos a elas não existiam para Norberto.

A sugestão de que o artista passava para sua personagem demandas próprias, apesar de tentadora, é por demais sensível. O que temos, de fato, é que ele vivia em uma sociedade com fortes restriçóes às sexualidades desviantes e o palco se mostrava como um lugar propício para essa vivência, ainda que por meio da personagem. Certamente nunca poderemos dizer quais foram os sentidos íntimos de sua escolha profissional, mas temos a possibilidade de através dela lançar luz sobre as alternativas e possíveis estratégias de muitas pessoas que em situaçóes parecidas não deixaram rastros. A trajetória de Norberto é a de um sujeito excepcional normal, no sentido proposto por Carlo Ginzburg (1987), que argumentou que a história de um sujeito pode revelar processos invisíveis de grupos e relaçóes sociais.

Também não é possível dissertar sobre sua orientação sexual, pois ele não a revelava ao público dos cassinos e dos teatros nos quais se apresentava. Ao contrário, a dúvida e o questionamento sobre sua sexualidade faziam parte do entretenimento do público, configurando mais uma ferramenta de trabalho para a atuação de Norberto. A dúvida inquietava o público, pois ele era um ator transformista que apenas no palco (e nunca publicamente fora dele) se vestia com roupas consideradas femininas.

Dessa maneira, é muito útil o conceito de "epistemologia do armário", cunhado por Sedgwick (2007), que consiste em apontar que ao manter a homossexualidade em sigilo seria possível acessar uma série de possibilidades embargadas a gays e lésbicas que tornaram pública sua orientação sexual. Enquanto isso, a presunção da homossexualidade apesar de provocar

\footnotetext{
${ }^{3}$ Revista Manchete (RJ), 26 set.1953.
} 
efeitos excludentes também geraria uma elasticidade de possibilidades, aparecendo como uma estratégia frente à hostilidade, à exclusáo e à violência. Assim, mais importante do que versar sobre a orientação sexual de Norberto, interessa-nos perceber como o artista, cuja personagem brincava com as percepçóes do público sobre as questóes de gênero, vivenciou possibilidades e limites na sua vida profissional.

A popularização do teatro, especialmente do gênero das revistas, como um meio de diversão nos anos de 1920 e a posterior importação do seu modelo de produção para o rádio fazia com que os conflitos das personagens transbordassem para o debate público nos centros urbanos (VERAS, 2017, p. 51-84). No contexto do surgimento do mercado de diversôes no Rio de Janeiro, a forma como Norberto expunha a relação conflituosa entre o masculino e o feminino foi determinante para que ele tivesse aceitaçáo e, em certa medida, respeitabilidade no nicho do mercado artístico. O diferencial de Norberto era sua forma de apresentação, pois se colocava como uma mulher linda, desejável, rica e talentosa, que perturbava e confundia os amantes "do belo sexo".

Figura 1: Imagem de divulgação da personagem Aymond



Fonte: O Dia (PR), "Aymond". 5 set. 1933

Norberto em seus shows de transformismo fomentava uma série de ideias e curiosidades no público. Trevisan (2002, p. 242-243) comenta que, para além de uma visão corrente de travestis como pessoas desordeiras e amorais, no início do século XX ocorreu um processo de profissionalização e elas ganharam outro status social. Marcando o transformismo como um oficio, ele aponta que "outra vertente do travestismo se voltou para um objetivo mais profissional, com o surgimento nos palcos do ator-transformista, que passou a viver profissionalmente da imitação das mulheres e, com frequência, tornou-se travesti também na vida

\footnotetext{
${ }^{4}$ Termo usado na época para tratar do feminino.
} 
cotidiana" (TREVISAN, 2002, p. 242-243).

Ao historicizar essa profissão, Trevisan defende que os artistas transformistas antecederam o grupo atualmente chamado de drag queens ou drag kings. O trabalho de Butler (2013) analisa a atividade das drags a partir da noção de gênero como performance, mostrando que com os traços exagerados das personagens se zomba da artificialidade da construção social do gênero. No período demarcado por este artigo, o trabalho artístico aparecia como um dos poucos espaços que, de forma mais ou menos livre, era possível subverter, fora do período do carnaval, as regras comportamentais de gênero sem grandes ônus sociais (VERAS, 2017).

Os shows de transformismo consistiam em performances que ocupavam cassinos, festas, circos e espetáculos teatrais de revistas. Humorísticas, elas eram também consideradas exóticas ou, até mesmo, imorais. Com intuito de brincar com as percepçóes do público sobre o masculino e o feminino, consistiam em metamorfizar o corpo do artista por meio de roupas, acessórios, maquiagens e trejeitos. Surpreendendo o público com a beleza e com a voz delicada, além de Norberto, Walter Bank e John Bridges se apresentaram em reconhecidos espaços de diversóes do Brasil imitando cantoras líricas e populares com muita fidelidade. Por meio do requinte e das apresentaçóes pomposas, esses artistas visavam se diferenciar dos transformistas marginalizados que trabalhavam no ramo das diversões. $\mathrm{O}$ reconhecimento dos artistas citados, ainda que de forma limitada, rendeu notícias de jornais que anunciaram suas apresentaçóes. Na contramão desses casos foi invisibilizada uma série de artistas transformistas menos talentosos e mais vulneráveis, como por exemplo, João Francisco dos Santos, conhecido como Madame Satã.

Entre o final da década de 1920 e o início da década de 1930, período em que Norberto estava no Rio de Janeiro, Madame Satã também trabalhou como transformista em teatros de revista da Praça Tiradentes e fazia serviços domésticos em bordeis da Lapa (RO$\mathrm{CHA}, 2004)$. Sabemos desse evento na sua trajetória porque ele se tornou um ícone da luta LGBTQIA+ já nos anos 1990 e sua biografia foi resgatada. Conhecemos bem os aspectos da malandragem e da valentia de Madame Satá, que o fez ser temido e lembrado, mas sabemos pouco de sua trajetória artística.

Este artigo, como um esforço para operar no limite entre os campos de estudos de gênero e do trabalho, mostra as dificuldades de Norberto se afirmar social e financeiramente no mercado artístico por conta do estigma de sua personagem. Sendo o acesso ao trabalho uma condição indispensável à vida e uma das grandes barreiras para a inclusão ampla de pessoas LGBTQIA+, é fundamental que a academia historicize essa exclusão. Os pesquisadores do chamado queer work, em diálogo com a renovação da história social do trabalho, tem respondido a essa demanda. Esses estudos recentes mostram a tentativa de entender as dificuldades da população LGBTQ+ no acesso ao trabalho e as vulnerabilidades e solidariedades construídas nesse interim. Podemos ilustrar esses esforços através do trabalho de Allan Bérubé (2011), que trata dos trabalhadores comissários de voo e seus desafios, sobretudo no 
contexto da epidemia de AIDS na década de 1980, e de Miriam Frank (2014), que estuda a organização sindical a partir da identidade LGBT. Esses estudos têm encontrado espaço tanto nos meios acadêmicos estadunidenses quanto na militância.

Assim, analisar o mundo do trabalho artístico como um queer work pressupóe mais do que delimitá-lo como um setor que empregava homossexuais. É necessário avaliar como as hierarquias desse setor eram construídas e de que maneira dinâmicas internas particulares influenciavam nos mecanismos de consagração e profissionalização. A exposição pessoal no mercado das diversóes era forte a ponto de transformar o corpo do artista em material e produto de trabalho. Por sua vez, o público tendia a fazer uma simbiose entre o artista e sua personagem, o que levava os artistas transformistas a viverem baixo suspeição moral. Veras (2017) defende, através dos exemplos de Norberto, Madame Satã e Francisco Alves, que apesar de as empresas artísticas e publicitários empregarem artistas homossexuais, a discrição e o sigilo eram importantes fatores para galgar bons contratos e sucesso nacional e internacional.

\section{$O$ artista "garganta de ouro"}

Norberto Américo Aymonino nasceu em 1902 na cidade de Dolores na Argentina. $\mathrm{O}$ nome artístico de Norberto era Aymond. Com essa personagem fazia shows de transformismo nos teatros, cassinos e em festas populares. Seus números envolviam belas roupas femininas e imitação da voz de cantoras famosas, brasileiras, portuguesas e argentinas. Assim, ele se diferenciava de outros artistas pobres e malvestidos que atuavam como transformistas por confundir o público com sua elegância, beleza e talento como cantor.

Pouco se sabe sobre sua trajetória, mas estima-se que a primeira vez que veio ao Brasil, exatamente ao Rio de Janeiro, foi em 1926. Ele integrava a "Companhia Argentina de Revistas", uma das mais luxuosas de Buenos Aires, em turnê dado um acordo comercial com o empresário Walter Pinto5. No fim do conjunto das apresentaçóes, como correntemente acontecia com os artistas viajantes, Norberto se separou do grupo. Sem a companhia portenha, ele se apresentou no Teatro Fênix com a peça A-E-I-O-U e depois sua pista foi perdida. Em 1928, temos novamente notícias de Norberto no Rio de Janeiro atuando como artista solo. Ele trabalhou no Teatro Recreio com a revista Palácio das Águias e dividiu o palco com Alda Garrido, Mesquitinha e Lydia Campos, cantora argentina. Estima-se que ele tenha passado longo tempo viajando, pois no início da década de 1930 fontes da imprensa mostram que esteve em diversos estados do Brasil.

Veras (2017), em sua tese de doutorado, teve o desafio de entender o mercado das di-

\footnotetext{
${ }^{5}$ Importante empresário teatral que atuava no Rio de Janeiro. Seu arquivo pessoal, que conta com muitos documentos de sua empresa, está na biblioteca da Funarte no Rio de Janeiro. Fundo Walter Pinto WPEspEPIMP/1950_14
} 
versões como um espaço de trabalho. Considerando o mundo do espetáculo como um ambiente diverso, a pesquisadora percebeu a presença de diferentes estratos sociais entre intérpretes e artistas de variedades. Ela apontou que, no contexto do crescimento do mercado de diversôes, a moralidade e a respeitabilidade eram características que transbordavam da personagem para o sujeito real. Assim, a áurea de cultura e intelectualidade boêmia que envolvia artistas mais bem colocados não alcançava quem interagia mais explicitamente com os setores subalternos da marginalidade, da prostituição e da ilegalidade. Norberto não tinha passagem na polícia, o que deixa claro que ele circunscrevia sua atividade nos meios legalizados do teatro, dos cassinos e das festas de caráter privado, renunciando a atuar em bordeis e outros espaços que poderia ser alvo de batida policial.

Norberto não teve problemas para conseguir emprego, inclusive trabalhou em lugares frequentados pela alta sociedade, mas não recebeu cachê condizente com os das estrelas com quem dividia o palco. Enquanto a imprensa nos permite saber quem esteve junto dele nas apresentaçóes, através da sua ficha de registro na Delegacia de Costumes e Diversões Públicas do Rio de Janeiro, exposta nas Figuras 2 e $3^{6}$, podemos nos aprofundar na questão salarial. Apesar de legalmente obrigatória, não eram todos os artistas que se registravam e nem todo empregador que a preenchia corretamente. Dessa maneira, os dados apresentados lançam luz sobre a questáo salarial dos artistas sem permitir conclusóes absolutas.

Figura 2: Frente da ficha de Norberto Américo Aymonino do Fundo da Delegacia de Costumes e Diversōes Públicas do Rio de Janeiro

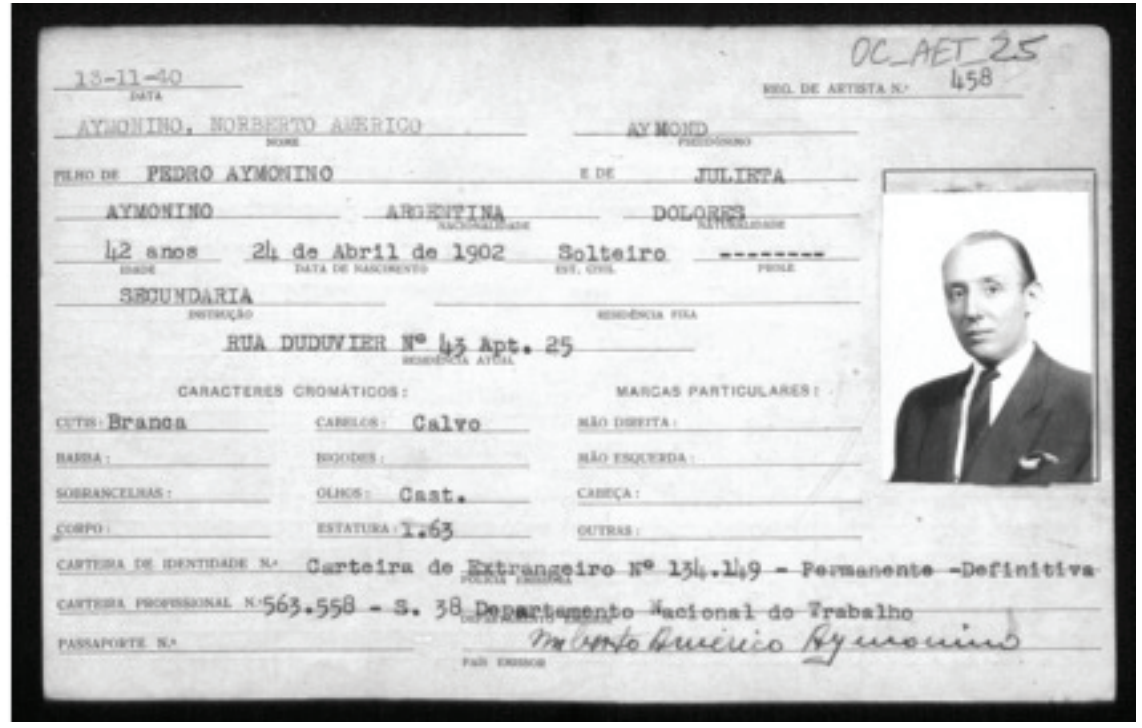

Fonte: Arquivo Público Nacional (RJ). Localização: BR RJANRIO OC.0.AET.25 - Dossiê

\footnotetext{
${ }^{6} \mathrm{O}$ documento está digitalizado e disponibilizado através da plataforma do Sistema de Informaçôes do Arquivo Nacional (SIAN)
} 
Figura 3: Verso da ficha de Norberto Américo Aymonino do Fundo da Delegacia de Costumes e Diversôes Públicas do Rio de Janeiro

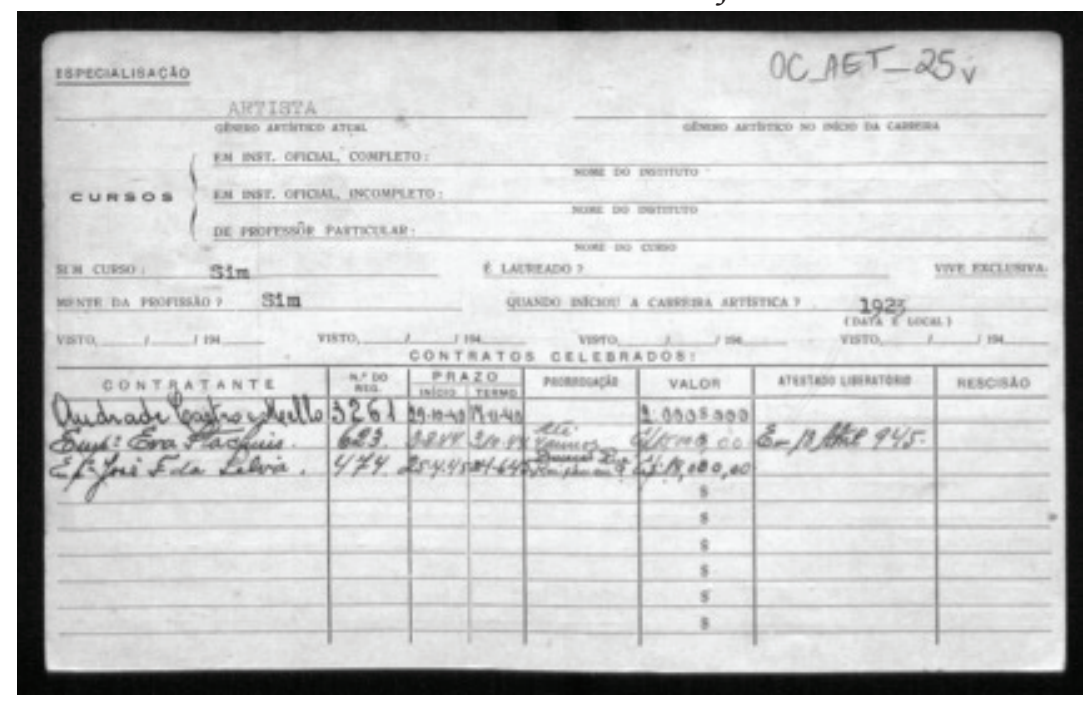

Fonte: Arquivo Público Nacional (RJ). Localização: BR RJANRIO OC.0.AET.25 - Dossiê

Segundo essa ficha sabemos que quando Norberto voltou ao Rio de Janeiro depois de algum tempo viajando pelo Brasil, trabalhou para a Companhia Andrade Mello, que fazia revistas para o público geral pelo período entre 29 de setembro de 1940 até o dia 17 do mês seguinte por dois mil cruzeiros. Após um período de quase quatro anos, no qual não sabemos se o contrato foi prorrogado ou o artista abandonou a empresa, ele foi registrado, em meados de 1944, na companhia teatral de Eva Stachino com um humilde ordenado de 15 mil cruzeiros por ano e possibilidade de prorrogação por quatro anos. Contudo, Norberto obteve seu atestado liberatório ${ }^{7}$ em 18 de abril 1945. O desligamento da empresa pode ter se dado por desejo do artista, já que no dia 24 de abril de 1945, apenas seis dias após a emissão do documento, foi registrado seu trabalho para a Empresa José F. da Silva, com salário fixo por "toda duração da peça apresentada", quando recebeu pagamento de 18 mil cruzeiros. A princípio esperava-se que a temporada durasse dois meses, mas era comum que houvesse prorrogações se a peça fizesse sucesso. Fato é que não há registro sobre o atestado liberatório e perdemos, mais uma vez, o rastro de Norberto $^{8}$. Esses ordenados não eram tão baixos

\footnotetext{
${ }^{7}$ Atestado liberatório era um dispositivo da Lei Getúlio Vargas, que regulamentava o trabalho do artista, que legislava sobre a quebra de contrato entre artistas e empresários. Segundo a lei, um artista apenas poderia se empregar por uma empresa se recebesse o atestado liberatório do antigo empregador. Caso infringisse o regulamento, o artista teria que ficar dois anos sem atuar ou pagar uma pesada multa. Apesar dessa disposição, muitos artistas partiam em turnês ou quando surgia a ameaça de serem denunciados, a falta de comunicação entre as Delegacias de Costumes e Diversóes Públicas dos estados, tal como a resistência de artistas e empresários a registrar minuciosamente as ocorrências, facilitavam essa prática.

${ }^{8}$ Ficha de Norberto Américo Aymonino, do Fundo da Delegacia de Costumes e Diversóes Públicas do Rio de Janeiro. Arquivo Público Nacional.
} 
quanto os das coristas que trabalhavam em péssimas situaçóes, mas sequer se comparava com o das artistas com quem ele dividia o palco principal como mostra a pesquisa de Veras (2017, p. 198-230).

Apresentando-se como uma bela dama da sociedade, Norberto despertava sentimentos controversos no público. Com seu talento de imitador de vozes e a habilidade de imprimir em Aymond o comportamento elegante e bom gosto, o artista desafiava o público, que se via obrigado a lidar com Norberto nos padróes masculinos e Aymond segundo os padróes femininos. Essa dicotomia entre artista-personagem foi importante na sua construção profissional. Em seus shows de transformismo imitava a voz de cantoras de sucesso mundial com tanta perfeição que recebeu o apelido de "o artista garganta de ouro". Esse codinome era usado para se referir às cantoras líricas de reconhecido talento. Quando aplicado para apresentar Aymond, assumia um duplo sentido, primeiramente zombando do artista ao atribuir a ele um elogio feminino, mas também reconhecendo seu talento como cantor.

\section{Amanhã no Th. Avenida}

A espectaculosa extréa que todos esperam ansiosamente.

\section{AYMOND (o garganta de ouro)}

O homem que usa trajes femininos com muito mais elegância, mais gosto e mais requinte que uma própria mulher. Um desafio ao mundo feminino com seu luxuosíssimo guarda-roupas avaliado em mais de duzentos contos de reis. $\mathrm{O}$ mais perfeito imitador do belo sexo.

\section{AYMOND}

Que possue maravilhosa voz de soprano Lyrico, imita com extraordinária perfeição as mais celebres cantoras mundiais, e as mais famosas estrelas de Hollywood ${ }^{9}$ (Grafia original)

Demarcando sua posiçáo de artista diferenciado, um dos traços mais comentados dos números de Aymond era o seu guarda-roupa "de mais de duzentos contos de reis". O alto valor pecuniário no qual estava avaliado o guarda-roupa do artista atraía muita curiosidade do público. Contudo, o rendimento de Norberto com os shows de transformismo não lhe oferecia o suficiente para tais luxos e suas turnês não incluíram viagens para a Europa ${ }^{10}$. Como Norberto fazia para ter esse guarda-roupa tão valioso? Certamente ele tinha um conhecimento razoável de corte e costura, o que lhe possibilitava ajustar ou mesmo criar suas roupas. Ele poderia ter, também, uma rede de cooperaçáo e amizade muito poderosa que lhe permitia esses investimentos profissionais tão importantes para a construção de sua personagem.

\footnotetext{
${ }^{9}$ O Dia (PR), 30 ago. 1933.

${ }^{10}$ Idem
} 
Em contraste com a ideia subversiva da personagem apresentada por Norberto, a questão da moralidade e do respeito a padrôes sociais normativos era uma preocupação entre os artistas. A partir da década de 1930, quando temos a ampliação de direitos trabalhistas, incluindo profissionais do tablado, e o incremento do mercado de diversóes, essa preocupação se intensificou. No caso de artistas, ampliaram-se os direitos, como também a fiscalização. A Delegacia de Costumes e Diversôes Públicas do Rio de Janeiro, a partir de 1932, tinha a missão de registrar quem se apresentasse nos palcos da cidade. Apesar da obrigação, essa não foi uma causa abraçada imediatamente pela maioria da categoria dos artistas. Ao contrário, continuaram sem registro até que, por algum motivo específico, que poderia ser desde uma demanda trabalhista até a imposição de algum empregador, sentiam a necessidade de fazê-lo.

No ato da apresentação era preenchida uma ficha por autodeclaração com informaçóes pessoais e trabalhistas, como é possível ver nas Figuras 2 e 3, que mostram a frente e o verso da ficha de registro. Era possível deixar itens em branco e não era necessário apresentar comprovação das informaçôes. Com isso alguns dados foram estrategicamente omitidos. Por exemplo, no Rio de Janeiro, ninguém, nem mesmo Norberto, declarou ser transformista. Ele se identificou apenas como "artista"

Assim, do ponto de vista legal ele pretendia preservar a sua imagem ocultando na delegacia que era transformista, ao mesmo tempo que pleiteava ser incluído nos benefícios sociais e trabalhistas que os artistas passaram a usufruir a partir da popularização da Lei Getúlio Vargas de $1928^{12}$, que regulamentava a profissão artística, e da fundação oficial do Sindicato dos Artistas em 1931. Norberto teve sua filiação aprovada no referido sindicato em 16 de maio de $1945^{13}$, quando mais uma vez não declarou ser transformista, mas cantor.

Enquanto no Rio de Janeiro Norberto ocultou sua especializaçáo de artista transformista, em Pernambuco ele não se preocupou com essa questâo. Ao se apresentar à Delegacia de Diversóes Públicas do estado, em 1941, em decorrência da participação na Festa da Mocidade ${ }^{14}$, identificou-se como "artista (transformista)". A primeira vez que temos registro de Norberto em Recife foi em 1938, quando se apresentou no cassino do luxuoso Grande Hotel.

Apesar de viajar bastante, Norberto tinha moradia fixa e rede de contatos profissionais e íntimos no Rio de Janeiro. Mesmo tendo estado em muitos estados do Brasil durante as décadas de 1920 e 1930, a capital é o lugar onde Norberto permanece mais tempo e para onde sempre retornava. No dia 13 de novembro de 1940, Norberto compareceu à Delegacia

\footnotetext{
${ }^{11}$ Ficha de Norberto Américo Aymonino, do Fundo da Delegacia de Costumes e Diversóes Públicas do Rio de Janeiro. Arquivo Público Nacional.

${ }^{12}$ Decreto 5.492 de 16 de julho de 1928.

${ }^{13}$ Livro de registro de artistas filiados. Arquivo privado do SATED-RJ.

${ }^{14}$ Festa de estudantes da elite recifense que se tornou uma celebraçáo anual com a presença de políticos e outras personalidades públicas.
} 
de Costumes e Diversôes Públicas do Rio de Janeiro para se registrar como artista e poder trabalhar legalmente. Por essa ocasiáo temos alguns dados oferecidos pele próprio Norberto. Ele se declarou solteiro, nesse período, morando na Rua Duvivier em Copacabana e estando no Brasil com visto permanente expedido pelo Departamento Nacional do Trabalho. ${ }^{15}$

O bairro de Copacabana, sobretudo a rua na qual ele declarou morar e suas imediações, era um espaço conhecido pela "modernidade" e por ser um local de encontro e sociabilidade de homossexuais (GREEN, 2019, p. 152-156). Dessa maneira, o local de moradia de Norberto permitia que ele tecesse relaçóes na vizinhança, ao mesmo tempo que no palco se diferenciasse de artistas transformistas mais vulneráveis.

No geral, os transformistas no Brasil náo conseguiram se afirmar como artistas de renome e acabaram esquecidos pelo público. Green (2019) apontou que a prostituição era uma possibilidade aos homens considerados afeminados, em uma geografia da cidade que envolvia parques, teatros, banheiros públicos, bordeis, hotéis e pensóes de artistas. A renúncia de circular em certos espaços, como nos parques durante a noite, ou a possibilidade de escolher trabalhar em espaços mais respeitáveis - teatros em detrimento de bordeis ilegais - tinha um poder de demarcaçáo social.

Por outro lado, Pinheiro (2015) defendeu que as características do "almofadinha", muito vinculada no senso comum ao homem delicado e "afeminado", poderia tomar ares de modernidade na figura dos dândis. Essa imagem é muito cara para pensar a forma com que Norberto se apresentava ao público e à imprensa, ou seja, como um artista moderno, a par da moda e das formas elegantes de se vestir e comportar. Enquanto Norberto, ele não nega a masculinidade, mas incontestavelmente a subverte em pontos subjetivos como a agressividade e o cuidado com a aparência.

Pelo menos até a década de 1940, Norberto nunca falou abertamente sobre sexualidade. Ele trabalhava como transformista e sua personagem, Aymond, apresentava-se como uma mulher perfeita, dado o talento e profissionalismo do artista - essa era toda a informação que tinham o público e a imprensa. Ele vestia roupas consideradas femininas apenas para atuar, fora do palco usava roupas tradicionalmente masculinas. Durante sua passagem em Recife para trabalhar na Festa da Mocidade, o jornal Diário da Manhã de Recife publicou:

Aymond é transformista, conforme anuncia o animador do espetáculo. E é transformista de verdade. Apresenta-se em toilette feminina (aliás, em linda toillete feminina), tem voz de mulher, corpo de mulher, pele de mulher, braços e pernas de mulher, mas Aymond, apesar de tudo isso, não é mulher, é homem. Na rua, está de calça, paletó, colarinho e gravata, embora conserve a pele, os braços, o corpo e as pernas de mulher. No palco, agrada com a sua

\footnotetext{
${ }^{15}$ Ficha de Norberto Américo Aymonino, do Fundo da Delegacia de Costumes e Diversões Públicas do Rio de Janeiro. Arquivo Público Nacional (RJ). Localização: BR RJANRIO OC.0.AET.25 - Dossiê
} 
camuflagem, que tanto impressiona. Aymond em certos casos é mulher e em outros, homem. Agora, pergunta-se: no caso de mobilização, qual seria a situação de Aymond, $o$ transformista? ${ }^{16}$ (Termo da fonte)

Mais uma vez temos a imprensa expressando através do duplo sentido a inquietação causada por Norberto/Aymond. A pergunta colocada na citação acima, "no caso de mobilização, qual seria a situação de Aymond, o transformista?", apela para que os leitores acabem pensando em Aymond tendo uma relação sexual. Contudo, a "mobilização" também poderia ser o serviço militar, que, dada a Segunda Guerra Mundial, estava convocando os homens, mas não as mulheres (ALBUQUERQUE JR., s.d).

Posteriormente aos eventos até agora relatados, após 1945 temos um profundo silêncio sobre Norberto, que será quebrado apenas a partir da década de 1950. Por conta da repaginação do teatro de revista com Walter Pinto e a peça É fogo na jaca, que consagrou a travesti portuguesa Ivaná no teatro carioca, a cena artística parece ter dado um novo engajamento para a questão das transformistas. Muitos consideram Ivaná como a primeira transformista do teatro brasileiro, talvez pela proeminência que ela teve na mídia ao tentar, em 1961, fazer cirurgia de resignação de sexo, sendo impedida no aeroporto de deixar o país para esse fim (NUNES, 2015, p. 166). Ivaná, em entrevista à revista Manchete, em setembro de 1953, tratou da questão das travestis nos teatros fazendo questão de lembrar de Aymond ${ }^{17}$ como a primeira travesti do Brasil e marcando que, apesar da idade (52 anos), ainda estava em atividade: "Antes de mim, os brasileiros tiveram ainda Aimo (sic), que apesar da idade avançada, ainda continua a trabalhar. Ele é o verdadeiro pioneiro" 18 .

Concomitantemente à publicação dessa entrevista, o último registro que temos de Norberto é seu desembarque de navio no porto do Rio de Janeiro em setembro de $1953^{19}$, mas sem detalhes sobre como ele vivia ou motivo da viagem, apenas sabemos que tinha visto temporário. Provavelmente novas investigações mais específicas sobre o tema de artistas transformistas possam dar mais pistas, não apenas sobre Norberto e Aymond, mas também sobre as condições de trabalho, reconhecimento na profissão e desafios particulares desse grupo.

O fato de ter sido lembrado por Ivaná mostra que Norberto participou de redes que conectavam artistas transformistas desconhecidas no mundo das celebridades e não encontradas nos arquivos tradicionais. A busca por fontes orais e por arquivos privados preservados pelos pares de Norberto pode ajudar a revelar novos aspectos da sua vida profissional e da estruturação do mercado de diversóes que empregava artistas transformistas e drags.

\footnotetext{
${ }^{16}$ Diário da Manhã, "A vida da Cidade. Aymond, o transformista e outros artistas". Recife/PE, 27 dez. 1941.

${ }^{17}$ Certamente por desconhecer o artista, a grafia de Aymond aparece como "Aimo".

${ }^{18}$ Revista Manchete (RJ), 26 set. 1953.

${ }^{19}$ Arquivo Nacional (RJ). Título: Assuntos Políticos: Entrada e Permanência de Estrangeiros: Permanência Definitiva: Norberto Americo Aymonino. Código de Referência: BR RJANRIO VV.0.0.1954005609
} 
Figura 4: Ficha de desembarque de estrangeiro

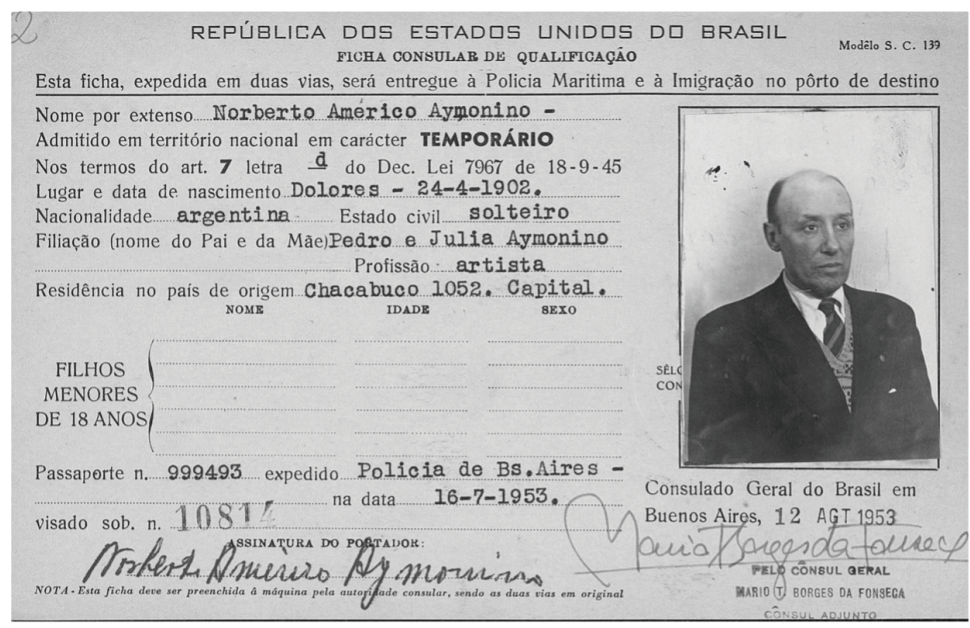

Fonte: Arquivo Nacional (RJ). Título: Assuntos Políticos: Entrada e Permanência de Estrangeiros: Permanência Definitiva: Norberto Américo Aymonino. Código de Referência: BR RJANRIO VV.0.0.1954005609²0

As fontes sobre Norberto no Brasil são muito recortadas e por vezes perdemos sua pista. Náo conseguimos saber as datas exatas de quando ele chegava, quem o recepcionava no Rio de Janeiro e em outras cidades do Brasil ou como entendia as brincadeiras da imprensa. As publicações sobre ele consistem na descrição jocosa de suas apresentaçôes, sem se aprofundar nos pensamentos, sentimentos ou escolhas do artista - como poderia acontecer se tivéssemos encontrado alguma entrevista cedida por ele.

Se os documentos encontrados no Brasil são escassos e insuficientes para adentrar na subjetividade de Norberto, na Argentina a situação documental é ainda mais nebulosa. Não foi possível localizar nos jornais coberturas sobre qualquer apresentação do artista nas cidades por onde passou, sequer é possível saber com exatidão quando ele viajava de volta para a Argentina. Sabe-se que realmente ele nasceu em Dolores, mas a inexistência de dados sobre ele nas associaçóes de atores, autores e empresários argentinos nos indica que não era popular como no Brasil. Fora da Argentina, Norberto poderia acionar sua condição de artista estrangeiro para reescrever sua própria história ao gosto do público, o que talvez não tivesse facilidade de fazer em sua terra natal.

\section{Conclusão}

No decorrer da leitura deste artigo foi possível lançar luz, através da trajetória profissional de Norberto Américo Aymonino, sobre como noções de gênero e suas formas de

\footnotetext{
${ }^{20}$ Documento digitalizado e disponibilizado através da plataforma do Sistema de Informaçôes do Arquivo Nacional (SIAN).
} 
manifestações criaram condiçóes especiais para os artistas transformistas projetarem suas ambiçóes profissionais na primeira metade do século XX no Brasil e, mais especificamente, no Rio de Janeiro.

Vimos que o estudo sobre a vida profissional de Norberto nos coloca a dificuldade de pesquisar sobre um tema com fortes restriçôes em sua época. Embora o transformismo fosse entendido como uma atividade no conjunto do mundo do trabalho dos espetáculos de diversóes, existia sobre ele suspeição moral e uma aceitação restritiva. Embora a homossexualidade não fosse tipificada como um crime, era atravessada pelo discurso médico, relegada à marginalidade e motivo de vergonha. Como um todo, vimos que o próprio mundo do trabalho artístico e popular, apesar de permitir certas liberdades, era policiado e disciplinarizado por meio da construção de delegacias especializadas e formas de controle específicas. O prestígio e os direitos sociais contemplavam os segmentos de artistas de formas diferenciadas. Geralmente, transformistas não chegavam a acessar plenamente os benefícios por conta do estigma e do preconceito.

Essa situação gerou uma dificuldade especial para buscar fontes - o que normalmente não ocorre quando pesquisamos artistas no geral. A vulnerabilidade dos transformistas faz com que evidências importantes não tenham sido preservadas por esforço do próprio sujeito estudado, que claramente se esforçou para manter sigilo sobre sua vida pessoal. $\mathrm{O}$ dilema das fontes no estudo de sujeitos subalternos não é novidade para quem atua no campo da história social do trabalho. Estamos acostumados a confrontar os silêncios das fontes, a vasculhar os subterrâneos em busca de evidências que nos possibilite ver a história ao rés do chão, mas inevitavelmente haverá brechas como nas tantas vezes que perdemos as pistas de Norberto.

No intuito de responder à questão colocada no início do texto foi feita uma breve comparação entre as trajetórias de Madame Satã e Norberto, visto que ambos exerceram a mesma atividade no espaço artístico. Essa comparação teve o intuito de evidenciar as estratégias de diferenciação construídas por Norberto. Madame Satã não teve as mesmas oportunidades que ele, tanto pelo seu comportamento confrontativo quanto pela ausência de características valorizadas na sociedade da época. Enquanto isso, Aymond, como personagem criada por Norberto, causava uma profunda perturbação no público. Além da beleza, o artista cantava em várias línguas, tinha um guarda-roupa elegante e era um estrangeiro branco - do país considerado o mais moderno e "civilizado" da América do Sul. Em contraste com Madame Satã, negro, pobre, violento, declaradamente homossexual, diariamente vestido com roupas femininas exuberantes e personagem conhecido da Lapa, Norberto tinha claras vantagens no tocante ao acesso ao mercado de trabalho formal.

Norberto, tal como os outros artistas transformistas citados neste texto, que estiveram em atividade na cidade do Rio de Janeiro, com exceção de Madame Satã, galgaram um espaço intermediário no complexo hierárquico do mercado das diversóes populares brasileira. 
Relembro que, dos que tiveram relativo sucesso, todos eram atores estrangeiros e brancos, ainda que com visto permanente no Brasil, características que segundo a pesquisa de Veras (2017, p. 231-241) era fundamental para uma posição de relevo no meio artístico. Esse balanço mostra que os mecanismos de consagração na profissão artística, como também a aceitação da transgressão nos palcos, passava por marcadores de classe e raça.

No entanto, esse tom de superioridade, cultura e requinte que Norberto apresentava em suas performances era parte da criação de sua personagem - Aymond. Há fortes indícios para afirmar que Norberto não era tão rico, luxuoso e requintado como fazia sua personagem parecer, mas esse era um traço importante para cativar seu público. Outra estratégia de Norberto foi manter sua vida pessoal como um assunto privado. Sem chocar o público ele transformava a dúvida em material importante a ser explorado na imprensa e nas suas apresentaçóes.

Esse jogo de suspeição parece ter sido um acordo tácito entre o artista, o público e a imprensa na marcação dos limites para o sucesso de Norberto como artista transformista. Ao mesmo tempo que ele fazia mistério sobre sua orientação sexual, aparecia fora do palco sempre usando roupas consideradas masculinas. A imprensa fazia o papel de ativar a dúvida e o debate entre os seus leitores através de anúncios com duplo sentido. Essa dualidade alimentava a curiosidade do público e mantinha Norberto/Aymond no circuito comercial, mas sem ofender diretamente o público mais conservador.

Assim, a narrativa de Norberto (e Aymond) ou de Aymond (e Norberto) é quase uma provocação do passado ao presente. Escrever sobre esse tema provoca um novo olhar para os objetos e sujeitos de pesquisa. O movimento ativista LGBTQIA+, desde os anos 1980 no Brasil, com os jornais Lampião da Esquina e Xana com Xana, começou a organizar a luta pela afirmação e visibilidade no país, mas por aqui esse movimento demorou um pouco para chegar na academia.

As pesquisas de Green (1999) e Trevisan (2002), como as primeiras a tratar das homossexualidades na história brasileira, apontam um vasto campo que só apenas recentemente tem sido objeto de pesquisa em ciências humanas. Investigadores de muitas áreas do conhecimento têm feito trabalhos interessantes sobre o tema. Para citar apenas alguns pesquisadores, temos, na história, Benito Schmidt (UFRGS), reconhecido pelo trabalho de interseção entre biografia e história; no direito, Renan Quinalha (UNESP), que trabalha com a relação entre a ditadura civil-militar e a perseguição a homossexuais; e, também na história, Elias Veras (UFAL), que estudou a estética travesti dos anos 1970-1980 em Fortaleza. Além de pesquisadores como Luiz Morando e Rita de Cássia Colaço Rodrigues, que fazem importante trabalho de catalogação e divulgação de documentos para novas pesquisas. Ambos têm estudos que são contribuições fundamentais para a memória homossexual e travesti. Rodrigues (2012) pesquisou as pautas políticas de "travestis, bonecas, viados, gueis e lésbicas na cena política brasileira" tendo como marco o ano de 1978 e a fundação do grupo SOMOS. 
Morando (2020), que é professor da Letras, tem trabalhado em pesquisas de resgate da memória das identidades LGBTQIA+ em Belo Horizonte. Ele tem em seu horizonte o trabalho sobre a travesti nordestina "Cintura Fina", que viveu na capital mineira.

Outros trabalhos poderiam continuar sendo citados para demonstrar o desenvolvimento e a dinâmica que os estudos LGBTQIA+ têm tomado no Brasil. O presente artigo se propôs a ser uma contribuição acadêmica nessa área, mas também lançar luz sobre a trajetória esquecida de Norberto/Aymond. Através da experiência do artista e de sua personagem Aymond, foi possível identificar, ainda na primeira metade do século XX, a objetificação e a penalização de corpos desviantes. Vimos que o mundo de trabalho artístico, em uma interseção entre a exploração e certa inclusão, favoreceu a construção da imagem de travestis como produto exótico, vendável e humorístico.

\section{Fontes documentais}

ARQUIVO NACIONAL. Fundo da Delegacia de Costumes e Diversões Públicas. Disponível em: http://obscurofichario.com.br. Acesso em: 5 dez. 2019.

ARQUIVO NACIONAL. Fundo do Serviço de Comunicaçôes do Ministério da Justiça e Negócios Interiores.

BRASIL. [Lei Getúlio Vargas]. Decreto n. 5.492 de 16 de julho de 1928.

FUNARTE (RJ). Fundo Walter Pinto, WPEspEPIMP/1950_14.

SATED-RJ - Sindicato dos Artistas e Técnicos em Espetáculos de Diversôes do Estado do Rio de Janeiro. Arquivo privado. Livro de registro de artistas filiados.

\section{Fontes periódicas}

Diário da Manhã. A vida da Cidade. Aymond, o transformista e outros artistas. Recife/PE, 27 dez. 1941.

O Dia (PR), 30 ago. 1933.

Revista Manchete (RJ), 26 set. 1953.

\section{Fonte das Imagens}

Figura 1

O Dia (PR), "Aymond". 5 set. 1933. Disponível em: http://memoria.bn.br/DocReader/ docreader.aspx?bib=092932\&pasta $=$ ano $\% 20193 \&$ pesq $=\&$ pagfis $=25140$ 
Figuras 2 e 3

ARQUIVO PÚBLICO NACIONAL (RJ). Ficha de Norberto Américo Aymonino do Fundo da Delegacia de Costumes e Diversões Públicas do Rio de Janeiro. Localização: BR RJANRIO OC.0.AET.25 - Dossiê. Disponível em: http://imagem.sian.an.gov.br/acervo/ derivadas/BR_RJANRIO_OC/0/AET/00025/BR_RJANRIO_OC_0_AET_00025_ d0001de0001.pdf

Figura 4

ARQUIVO PÚBLICO NACIONAL (RJ). Assuntos Políticos: Entrada e Permanência de Estrangeiros: Permanência Definitiva: Norberto Américo Aymonino. Código de Referência: BR RJANRIO VV.0.0.1954005609

\section{Referências}

ALBUQUERQUE JÚNIOR, Durval Muniz de. “O Belo Golpe” ou por que os farsantes temem a farsa e os farsistas. S.d. Disponível em: http://obscurofichario.com.br/artigo/o-belo-golpeou-por-que-os-farsantes-temem-a-farsa-e-os-farsistas/. Acesso em: 5 jul. 2020.

BERUBÉ, Allan. My desire for history. Essays in Gay, Community, and Labor History. Edited by John D'Emilio and Estelle B. Freedman. Chapel Hill, NC: University of North Carolina Press, 2011.

BUTLER, Judith. Problemas de gênero: feminismo e subversão de identidade. Rio de Janeiro: Civilização Brasileira, 2013.

DUBERMAN, Martin B. Stonewall. New York: Penguin Group, 1994.

FORTES, Alexandre. O processo histórico de formação da classe trabalhadora: algumas consideraçóes. Revista Estudos Históricos, Rio de Janeiro, v. 29, n. 59, p. 587-606, nov. 2016.

FRANK, Miriam. Out in the Union: a Labor History of Queer America. Philadelphia: Temple University Press, 2014.

GINZBURG, Carlo. O queijo e os vermes: o cotidiano e as ideias de um moleiro perseguido pela Inquisição. São Paulo: Companhia das Letras, 1987.

GREEN, James. Beyond Carnival: Male Homosexuality in Twentieth-Century Brazil. Chicago \& London: The University of Chicago Press, 1999.

NUNES, Diego. Cá e lá: o intercâmbio cinematográfico entre Brasil e Portugal. São Paulo: Matarazzo, 2015.

MORANDO, Luiz. Enverga, mas não quebra: Cintura Fina em Belo Horizonte. Uberlândia (MG): O Sexo da Palavra, 2020. 
PERROT, Michelle. Os excluídos da história. Operários, mulheres e prisioneiros. Rio de Janeiro: Paz e Terra, 2017.

PINHEIRO, Larissa Brum Leite Gusmão. Melindrosas e almofadinhas de J. Carlos: questóes de gênero na revista Para Todos... (1922-1931). Dissertação (Mestrado em História) - Setor de Ciências Humanas, Letras e Artes. Universidade Federal do Paraná, Curitiba, 2015.

ROCHA, Gilmar. O Rei da Lapa, Madame Satã e a malandragem carioca: uma história de violência no Rio de Janeiro dos anos 30-50. Rio de Janeiro: 7Letras, 2004.

RODRIGUES, Rita de Cássia Colaço. De Daniele a Chrysóstomo - quando travestis, bonecas e homossexuais entram em cena. Tese (Doutorado em História) - Universidade Federal Fluminense, Instituto de Ciências Humanas e Filosofia, Departamento de História, Niterói, 2012.

SCOTT, Joan. Gender: a useful category of historical analyses. Gender and the politics of history. New York, Columbia University Press, 1989.

SPARGO, Tamsin. Foucault e a teoria queer; seguido de Agape e êxtase: orientaçôes pósseculares. Belo Horizonte: Autêntica Editora, 2017.

SEDGWICK, Eve Kosofsky. A epistemologia do armário. cadernos pagu, n. 28, p. 19-54, jan.-jun. 2007.

TREVISAN, João Silvério. Devassos no paraíso: a homossexualidade no Brasil, da colônia à atualidade. 5 ed. Rio de Janeiro: Record, 2002.

VERAS, Flavia R. "Fábricas da alegria" - O mercado de diversóes e a organização do trabalho artístico no Rio de Janeiro e Buenos Aires (1918-1945). Tese (Doutorado em História, Política e Bens Culturais) - Centro de Pesquisa e Documentação de História Contemporânea do Brasil (CPDOC), Rio de Janeiro, 2017.

VILELA, Márcio Ananias Ferreira. Anais do 30 Simpósio Nacional de História - História e o futuro da educação no Brasil. Recife: Associação Nacional de História - ANPUH-Brasil, 2019. 